\title{
O ADOLESCENTE DIANTE DA TELENOVELA
}

\section{Família, escola, amigos fazem parte da realidade sociocultural de adolescentes do meio urbano e rural e têm papel fundamental no potencial crítico que eles desenvolvem frente à TV}

O espaço que a mídia ocupa em nosso cotidiano tem se tornado objeto constante nas pesquisas sociais. Os estudos sobre os efeitos dos veículos de comunicação, em especial os poderes da televisão, ocupam as discussões de pesquisadores das mais diversas áreas. Um grande número dessas pesquisas, em especial durante as décadas de 60 e 70, apontaram a televisão como responsável pelo desenraizamento cultural, pela alienação e até pela violência social. Enquanto pesquisadores buscam dimensionar o poder deste veículo, o grande público se deleita em frente à telinha.

Dentro da programação da TV brasileira, a telenovela desponta como fenômeno nacional. Este gênero cresceu a passos largos e rapidamente ganhou o coração do grande público. Detentor de altos índices de audiência, o gênero tornou-se alvo de inúmeras pesquisas tanto no Brasil como na América Latina.

No Brasil o gênero foi introduzido primeiramente pelo rádio em 1944 e a passagem do sucesso da radionovela para a televisão se deu na década de 50. Desde então, o gênero passou por numerosas alterações, adquiriu características locais, ganhou investimentos em tecnologia e em padrão de qualidade, tornando a telenovela brasileira inconfundível. Ganhou o mundo e passou a ser o nosso principal produto de exportação cultural. A força da telenovela pode ser mensurada por um cartaz que se encontrava nas paredes da TV Globo, a respeito do sucesso de suas novelas na China: "Na conquista, uma arma mais poderosa que a pólvora - a emoção"'.

O sucesso da telenovela, tal qual a conhecemos hoje, pode ser atribuído ao fato de ela possibilitar ao telespectador uma identificação com o seu cotidiano, funciona como um espelho da realidade. A telenovela parece colocar um pouco de fantasia na vida real e um pouco de realidade na fantasia.

Para entender o fenômeno muitos estudos vêm sendo feitos e relacionam, principalmente, as mulheres com a telenovela ou, ainda, a família de uma forma geral. Este artigo busca entender a relação do adolescente com a ficção proporcionada pelas telenovelas. Qual o tipo de relação que o público mais jovem mantém com essa programação? Quanto tempo dedica a esse entretenimento? Mantém sonhos e ilusões baseados na temática das novelas? Por fim, qual o papel da telenovela na vida desse público e em que dimensão esse gênero atua em seu cotidiano?

\section{A AUTORA}

\section{Maria de Fátima Faila Elias}

Mestre em Comunicação Social pelo Instituto Metodista de Ensino Superior, SP. Professora do curso de Comunicação Social da Universidade Metodista de Piracicaba, SP. 
Para levantar hipóteses sobre as perguntas acima explicitadas, foi preciso conhecer as raízes, o desenvolvimento e a linguagem da produção ficcional. $\mathrm{O}$ objeto foi construído sobre dois pilares: o primeiro, a definição do perfil do adolescente contemporâneo: o que ele pensa, faz, onde e como vive. Para tal fez-se necessário conceituar a adolescência, estabelecer faixa etária, segmentar esse público por referências socioculturais. O segundo, tratou da construção histórica do gênero em questão, buscando compreender seu desenvolvimento e sua participação na sociedade.

Por acreditar na influência da condição sociocultural na forma de se relacionar com a programação televisiva, que pode ocasionar diferentes abordagens e leituras de uma mesma mensagem transmitida pela telenovela, optei por trabalhar em dois pólos culturais distintos, ou seja, foram pesquisados adolescentes rurais e adolescentes urbanos. O objetivo principal desta segmentação é demonstrar o valor da recepção, a possibilidade de uma decodificação individualizada, descartando, assim, as teorias de domínio e massificação.

Busca-se demonstrar que a mensagem transmitida pelo produtor não é absorvida de forma pura e integral, sofre alterações segundo os referenciais particulares e coletivos, que têm suas bases em importantes instituições socializadoras como a família, o grupo de amigos e a escola. Referências que independem dos veículos de comunicação e de sua produção.

A necessidade deste estudo pode ser percebida simplesmente analisando-se o perfil das novelas globais que, já na década de 70 , criaram um horário dirigido ao público ado- lescente, conhecido como o horário das 19 horas. Nos primeiros anos da década de 90 , nota-se um crescente número de atores jovens, talvez mais uma estratégia da emissora para envolver e capturar essa faixa de audiência.

A realização deste trabalho encontrou alguns obstáculos. Poderia ressaltar como principal a dinâmica que envolve o objeto, pois o adolescente está em constante mudança, é característica marcante desta faixa etária a busca, o movimento e a transformação. Nesta fase da vida, há uma otimização da dinâmica humana, as alterações são mais bruscas e repentinas. Há de se considerar, também, o contexto social que influencia diretamente o objeto, podendo frear ou acelerar essa dinâmica.

No que se refere ao estudo de novelas, o tempo também se torna um inimigo, pois esse é um produto cultural em constante mutação, tornando a linha entre o atual e o superado muito tênue. Deve-se atentar também para a relação pesquisador/objeto, podendo gerar influências e leituras equivocadas. $\mathrm{O}$ pesquisador deve estar atento não apenas para tabular as evidências; há de estar preparado para perceber o subtexto, as entrelinhas, tomando o devido cuidado para não dar margens a um processo meramente especulativo, uma vez que "quando pretendemos isolar um aspecto da personalidade humana, estamos sujeitos a erros"2.

\section{ORGANIZAÇÃO DA PESQUISA}

A pesquisa realizou-se na cidade de Piracicaba, estado de São Paulo, localizada a $170 \mathrm{~km}$ da capital. A escolha desta cidade, dentro do contexto do trabalho, não teve nenhuma função específica. O motivo que di- 
recionou esta escolha foi a facilidade para a pesquisadora organizar seus grupos de adolescentes para a observação e convivência.

Piracicaba tem sua população assim distribuída:

QUANTO À RESIDÊNCIA ${ }^{3}$

\begin{tabular}{ccc}
\hline População & $\begin{array}{c}\text { Números } \\
\text { Absolutos }\end{array}$ & Porcentagem \\
\hline Rural & 13.522 & $4,6 \%$ \\
Urbano & 286.958 & $95,4 \%$ \\
Total & 300.480 & $100 \%$ \\
\hline
\end{tabular}

POR SEXO - $1994^{4}$

\begin{tabular}{ccc}
\hline Sexo & $\begin{array}{c}\text { Números } \\
\text { Absolutos }\end{array}$ & Porcentagem \\
\hline Homens & 149.402 & $49,72 \%$ \\
Mulheres & 151.078 & $50,27 \%$ \\
Total & 300.480 & $100 \%$ \\
\hline
\end{tabular}

POPULAÇÃO ADOLESCENTE
DE PIRACICABA, SP
POR SEXO/FAIXA ETÁRIA - 19805
\begin{tabular}{rcccc} 
POR & 19. \\
\hline Idade & Masculino & Feminino & Total & $\%$ \\
\hline 10 a 14 & 10.928 & 10.462 & 21.390 & 10,2 \\
15 a 19 & 11.978 & 11.552 & 23.030 & 10,6 \\
Total & 22.906 & 22.014 & 44.420 & 20,8 \\
\hline
\end{tabular}

O trabalho de campo iniciou-se com a formação de dois grupos de adolescentes, um urbano e outro rural. Para organizar estes grupos buscou-se o universo escolar. A idéia de vincular este trabalho à escola não é gratuita. Primeiro, a escola é, sem dúvida, o lugar mais fácil de se localizar o público adequado à pesquisa. Segundo, porque os jovens do grupo já compartilhavam certa in- timidade entre si, sendo que este fator foi bastante positivo para que se sentissem mais à vontade durante os encontros da pesquisa. Terceiro, porque, tendo como intermediária a escola, o trabalho ganhou maior credibilidade frente aos adolescentes e seus pais. Foi importante também para a pesquisadora, que contou com uma participação mais efetiva dos alunos.

Dentro deste contexto a pesquisa com o grupo rural realizou-se em uma região denominada Serrote, localizada a $20 \mathrm{~km}$ do centro de Piracicaba. Esta comunidade foi escolhida porque ali se encontra a única escola rural da região que tem classes até à oitava série, onde foi possível encontrar adolescentes da faixa etária que interessava a este trabalho. $\mathrm{O}$ grupo urbano foi constituído em uma escola particular localizada no centro de Piracicaba. Importante ressaltar que, mesmo a escola rural sendo estadual e a urbana particular, há certa igualdade no que se refere à média socioeconômica dos alunos.

Durante a primeira etapa, os grupos pesquisados forneceram o embasamento para a parte quantitativa da pesquisa, através da qual foram traçados os dados gerais como: sexo, idade, condição econômica e cultural, perfil familiar bem como hábitos relativos à programação televisiva, passíveis de serem quantificados.

Numa outra etapa esses grupos tornaram possível efetivar a análise qualitativa do trabalho através da pesquisa-ação. Para esta fase a pesquisadora manteve encontros semanais com ambos os grupos por um período de três meses. Nesses encontros, o objetivo

3. CEMUPLAN. Piracicaba em números. 1994 (mimeo).

4. idem. ibd.

5. BILAC, M. Beatriz. Piracicaba: acervo de publicações especiais e dossiê de informações regionais. Piracicaba, Unimep, 1991 . 
era conhecer o universo adolescente, sendo que os assuntos desenvolvidos eram, muitas vezes, conduzidos pelos interesses do próprio grupo. Nesse momento, o papel da pesquisadora era relacionar tais interesses com a telenovela, produzindo assim discussões relacionadas a esta programação, mas sempre tomando como base os interesses e a fluência do próprio grupo.

O uso do vídeo se fez presente em nossos encontros, foi usado para assistirmos juntos a capítulos da novela indicada pela preferência do grupo, na época $A$ viagem, de Ivani Ribeiro, veiculada no horário das 19 horas pela $T V$ Globo. O vídeo foi recurso necessário devido à impossibilidade de assistirmos à novela em tempo real, principalmente na zona rural, pois sua transmissão já no início da noite, tornava inviável a reunião do grupo em um lugar comum, a distância, o transporte e o horário se constituíram em problemas que não pudemos solucionar, daí recorrermos ao vídeo.

Visto que a organização dos grupos se deu atráves da escola, houve procedimentos interdisciplinares, cujos trabalhos, desenvolvidos pelas disciplinas, colaboravam para a construção do perfil adolescente. Como exemplo posso citar um trabalho de redação para a disciplina Português, com o tema adolescência, ao qual tive acesso e que foi de muita valia para a pesquisa. Ou ainda uma pequena encenação desenvolvida pela professora de Educação Física, com o mesmo tema. Para essa encenação os adolescentes escolheram como trilha sonora a música Xote das meninas (Zé Dantas e Luís Gonzaga), dando-me uma pequena mostra do que representa a adolescência para seus próprios atores.

Nesta fase da pesquisa, também foram elaborados alguns jogos com o objetivo de perceber o grau de lembrança que os adolescentes tinham sobre telenovelas passadas e atuais, possibilitando detectar o grau de envolvimento dessa faixa etária com o gênero. Houve também alguns encontros informais, nos quais a pesquisadora participou de atividades de interesse do grupo, com o objetivo de aproximar pesquisador/pesquisado, facilitando assim o processo de observação.

A faixa etária delimitada para este trabalho ficou entre 13 e 17 anos, sendo condição importante que cada participante tivesse nascido e crescido dentro do universo cultural estabelecido. Ou seja, um adolescente do grupo rural não poderia já ter vivido dentro do contexto urbano, sendo o inverso também verdadeiro, pois o adolescente com uma experiência mista entre as duas culturas poderia gerar um terceiro parâmetro para o estudo, fato que foi descartado.

\begin{tabular}{cccc|ccc|c} 
& \multicolumn{3}{c|}{ URBANO } & \multicolumn{3}{c|}{ RURAL } & TOTAL \\
\cline { 2 - 8 } & Masc. & Fem. & Total & Masc. & Fem. & Total & \\
\hline 13 anos & 0 & 2 & 2 & 0 & 0 & 0 & 02 \\
14 anos & 0 & 3 & 3 & 6 & 5 & 11 & 14 \\
15 anos & 6 & 7 & 13 & 1 & 1 & 2 & 15 \\
16 anos & 0 & 0 & 0 & 4 & 2 & 6 & 06 \\
17 anos & 0 & 1 & 1 & 0 & 0 & 0 & 01 \\
Total & 6 & 13 & 19 & 11 & 8 & 19 & 38 \\
\hline
\end{tabular}




\section{UNIVERSO DA PESQUISA}

O universo pesquisado está assim delimitado quanto a sexo/idade e escolaridade:

\section{ESCOLARIDADE}

\begin{tabular}{lcc}
\hline & Urbano & Rural \\
\hline $6^{\mathrm{a}}$ série & $11 \%$ & - \\
$7^{\mathrm{a}}$ série & $16 \%$ & - \\
$8^{\mathrm{a}}$ série & $21 \%$ & $100 \%$ \\
$1^{\circ}$ colegial & $47 \%$ & - \\
$2^{\circ}$ colegial & $5 \%$ & - \\
\hline
\end{tabular}

Os dados acima já começam a delimitar algumas diferenças entre os dois universos. Nota-se que foi possível concentrar na oitava série do primeiro grau todo o grupo rural pesquisado, a diversidade da faixa etária neste universo se dá pelo fato de $42 \%$ da amostra se encontrar em atraso escolar. Já no universo urbano a escolaridade está pulverizada entre sexta série do primeiro grau até segundo colegial. $\mathrm{O}$ atraso escolar rural tem seus motivos: a mão-de-obra nas pequenas propriedades se configura como familiar, todo o trabalho conta com o auxílio dos filhos, $64 \%$ dos adolescentes rurais pesquisados declararam trabalhar, sendo que destes, $88 \%$ trabalham com a própria família.

No universo urbano apenas $16 \%$ dos entrevistados trabalham, $84 \%$ têm como responsabilidade apenas os estudos, demostrando que a formação escolar tem um peso maior neste universo, ao passo que no mundo rural os adolescentes assumem a responsabilidade do trabalho muito mais cedo, dedicando-se menos aos estudos.

É importante destacar que $63 \%$ dos adolescentes urbanos buscam complementar sua formação com atividades extracurriculares.
As mais citadas são cursos de línguas e informática. Já no universo rural, os adolescentes têm apenas a educação formal, não por falta de vontade, muitos expressaram o desejo de realizar outras atividades, em especial a computação. A impossibilidade destas atividades extras tem causas óbvias: falta de tempo, problemas com distância e locomoção. A escolaridade familiar, representada pelo pai e mãe do grupo rural, está concentrada no primeiro grau com um índice de $88 \%$. Já no universo urbano, $44 \%$ dos pais apresentaram sua formação no primeiro grau, $16 \%$ concluíram o segundo grau e $32 \%$ apresentaram formação em nível superior ou ainda pós-graduação. A escolaridade familiar vem reforçar a idéia colocada pelos dados anteriores, demostrando a valorização dos estudos no meio urbano.

Quanto à atividade profissional da mãe, os dados declaram a manutenção da família patriarcal no universo rural, $90 \%$ das mães foram classificadas como do lar, enquanto no universo urbano esse número cai para $37 \%$. Os pais dos adolescentes rurais têm suas atividades naturalmente concentradas na agropecuária, sendo $74 \%$ proprietários e $11 \%$ administradores de fazendas, totalizando $85 \%$. Do percentual restante, $5 \%$ declaram o pai como comerciante, $5 \%$ aposentado e $5 \%$ não responderam.

Já no grupo urbano a diversidade profissional apresentou as seguintes atividades: agrônomo $5 \%$, engenheiro $5 \%$, empresário $11 \%$, comerciante $11 \%$, motorista $5 \%$, metalúrgico $22 \%$, marceneiro $5 \%$, pintor $5 \%$ e desempregado $5 \%$. As atividades profissionais dos pais de ambos os grupos sinalizam a presença de representantes de diversas faixas econômicas no universo pesquisado.

A construção deste breve perfil do contexto socioeconômico dos adolescentes pesquisados explicita um alto nível de diferenças entre o rural e o urbano. Essas dife- 
renças ficaram ainda mais evidentes durante a pesquisa-ação, período em que pude vivenciar o reflexo de toda essa estrutura no cotidiano e no desenvolvimento desses adolescentes.

Como essas diferenças se refletem no comportamento, na relação com a TV e, em especial, com a ficção apresentada pela telenovela foi o que buscamos verificar.

\section{OS ADOLESCENTES PIRACICABANOS E A TELENOVELA}

O comportamento dos adolescentes rurais e dos adolescentes urbanos em relação à televisão e à telenovela por vezes se assemelha e por outras se distancia. Apesar de estes grupos apresentarem estilos de vida bastante diferenciados, como pode ser observado na descrição dos dois universos, a grande maioria dedica diariamente de $1 \mathrm{~h} 30$ a $2 \mathrm{~h}$ de seu tempo à televisão. Os índices, nesta faixa, são $47 \%$ para o rural e $42 \%$ para o urbano. Mesmo que os números entre o rural e o urbano não pareçam tão distantes, há diferenças fundamentais na maneira como este tempo é usado. A declaração de um adolescente urbano é reveladora:

"Nunca assisto a um programa ou a uma novela do começo ao fim, tenho coisas mais importantes para fazer do que ficar sentado na frente da televisão" (Bruno, 15 anos, urbano).

No grupo urbano, os adolescentes assistem à televisão aos poucos, entre uma atividade escolar e uma atividade esportiva ou extracurricular. $\mathrm{O}$ adolescente urbano não permanece em casa por um longo tempo. Ele passa pela sua casa entre uma atividade e outra, chega da escola, almoça, vê um pouco de TV e logo vai para a aula de computação ou inglês; chega do inglês, mais um pouquinho de TV e logo sai para jogar vo- leibol ou visitar um amigo. A mobilidade e o grande número de atividades que o universo urbano oferece fazem com que este adolescente não se prenda por muito tempo, de forma contínua, à televisão.

Já no universo rural, os adolescentes, ao fim de seu horário escolar, não têm mais nenhuma atividade educacional ou esportiva, têm muito trabalho esperando no sítio. Assim, ao chegarem da escola, almoçam e vão cumprir suas obrigações, as quais só terminam ao final da tarde. Aí é banho, jantar e televisão. Nesse caso, o tempo diário dedicado à TV é contínuo; representa lazer e descanso. Esse comportamento pode ser confirmado pela programação preferida pelos dois grupos. O grupo rural tem sua preferência concentrada nas novelas, com 39\% e nos filmes com $35 \%$, típica programação noturna. Já no grupo urbano, a preferência por novelas cai para $19 \%$ e os filmes e telejornais aparecem empatados com $23 \%$. Foram citados, também, programas de esportes, talkshows e seriados como Confissões de adolescente, Barrados no baile e Anos incriveis, ou seja, há uma pulverização dos horários e programações vistas.

No caso do adolescente urbano, a TV ocupa os espaços vazios, quando não se tem nada melhor para fazer. No rural, a TV acaba sendo a única opção. A forma fragmentada, pela qual o adolescente urbano assiste à televisão, colabora para que ele se envolva menos com este veículo, pois a mensagem televisiva é entrecortada por uma série de outras atividades, dispersando assim o seu interesse.

O autor de novelas Walter Negrão também vê a relação do adolescente com a telenovela como uma relação muito superficial: "É muito difícil você criar um hábito no público jovem, porque o público jovem muda 
mais rápido que a televisão. Quando você pensa que o conquistou com Armação ilimitada, vem uma MTV, com DJ's, clip em cima de clip, a alta fragmentação. Toda uma linguagem que não pede seqüência, e isso não cabe na telenovela. É um público muito difícil, você pega, o difícil é mantê-lo"6.

Estas afirmações traçam exatamente o perfil do adolescente urbano detectado nesta pesquisa, mostrando a descontinuidade existente na maneira em que este público usa a programação televisiva. O lançamento da soap opera Malhação pela Rede Globo também pode acenar neste sentido. Fugindo dos moldes tradicionais da telenovela brasileira, Malhação não apresenta capítulos que se interdependem continuamente. A cada semana os personagens vivem uma nova história, fato que acaba por resolver dois problemas em relação ao público jovem. O primeiro, diz respeito à descontinuidade da audiência, o segundo, às constantes mudanças de interesses pelas quais passa esse público.

Quando questionados diretamente sobre novelas, os dois grupos apresentam grandes diferenças. No grupo rural, $84 \%$ afirmam assistir novela; no urbano, este número cai para $42 \%$.

A diferença não está apenas nos números, mas também no posicionamento crítico frente a essa programação. A maioria dos adolescentes do grupo urbano questiona a qualidade deste tipo de programação, criticando a forma como as tramas se desenvolvem e o perfil dos personagens. Percebe-se certa resistência em assumir esse tipo de programação como uma atividade apreciada principalmente pelo adolescente acima de 15 anos. Ficou claro durante as investigações que, no ambiente urbano, na fase em que o adolescente começa a ter maior mobilidade, gerenciando seus próprios horários, ele se afasta desse tipo de programação. Esse fato pode ser verificado em vários momentos da pesquisa. $\mathrm{O}$ adolescente urbano, quando adquire uma certa autonomia, fica menos tempo frente à televisão e, por consequiência, a telenovela tem sua audiência reduzida na faixa etária entre os 15 e 17 anos.

Evidentemente esta faixa de idade não é estanque, tem variações que dependem do núcleo familiar: há pais que delegam responsabilidades ao filho mais cedo, outros um pouco mais tarde. Este fato também foi percebido quando os adolescentes urbanos foram submetidos a um jogo de memória, no qual deveriam descrever os personagens de uma novela que estava sendo exibida.

Os adolescentes de 13 e 14 anos saíram-se bem, conseguindo descrever quase a totalidade dos personagens que foram indicados. Já os adolescentes de 15, 16 e 17 anos conseguiram descrever apenas os personagens principais, mostrando assim terem menos intimidade com a trama da novela. Outro exercício de memória que corrobora com estes resultados diz respeito às novelas antigas; os jovens dos 15 aos 17 anos apresentaram uma memória relativa às novelas veiculadas entre 84 e 92 . Bastava mencionar o título da obra para que se lembrassem dos personagens, da trama, das músicas e da abertura, com margem de acerto altíssima, ou seja, eles carregam uma memória de telenovela dos sete aos treze/quatorze anos.

No grupo rural, não há essa subdivisão da adolescência no que diz respeito ao envolvimento com a telenovela, pois todos os adolescentes apresentaram uma memória passada e uma memória atual dessa programação. Mantendo uma linearidade, 90\% dos adolescentes conseguiram descrever todos $\mathrm{o}$; personagens que the foram colocados no jogo da memória. 
Esta diferença entre o grupo rural e o urbano é uma decorrência sociocultural, com ênfase nas diferentes oportunidades que cada universo apresenta. A criança rural já é acostumada desde cedo a uma rotina de responsabilidades, ajudando o pai e a mãe, como já foi demostrado anteriormente. $\mathrm{Na}$ passagem da infância para a adolescência pouca coisa muda, há um relativo aumento das reponsabilidades, mas nada que altere substancialmente seu comportamento ou sua rotina. Considerando também que o universo rural não oferece outras oportunidades, a estabilidade na rotina cotidiana do adolescente faz com que o relacionamento dele com a televisão também se mantenha sem alterações. Pode ser considerado como uma audiência estável durante toda a faixa etária pesquisada neste trabalho.

Já a criança e o adolescente urbanos têm suas responsabilidades centradas no universo educacional e, com a chegada da adolescência, mais atividades extracurriculares são assumidas. Alguns começam a trabalhar, mais tempo fora de casa ele permanece, portanto. $\mathrm{O}$ adolescente urbano tem uma alteração mais brusca de comportamento. Há, também, outros motivos que colaboram na mudança de rotina do adolescente urbano. Este universo lhe oferece um grande leque de opções de lazer e fácil locomoção entre um lugar e outro. É fator importante o recorte cultural que envolve a passagem da infância para a adolescência, no meio urbano. A criança, que até então era controlada e privada de responsabilidades que não se relacionassem à escola, passa a ser cobrada pelas suas atitudes sociais, éticas, morais e econômicas, devendo se tornar alguém mais responsável e maduro quase do dia para a noite. Começa a ter mais autonomia sobre seus horários e, como consequiência, passa mais tempo longe da televisão. Fica fácil compreender, então, o porquê do afastamento do adolescente urbano de programações televisivas como a novela, após os 14/15 anos de idade.

É perceptível e merecedor de destaque o fato de que, tanto no ambiente urbano quanto no rural, cada qual dentro da sua estrutura sociocultural e econômica, têm a relação com a TV comandada pelas suas rotinas diárias, e não o inverso, no qual a TV determinaria $o$ agendamento da rotina do dia-a-dia, determinando horários e ações cotidianas.

Mesmo os adolescentes rurais não hesitam em afirmar que, se tivessem oportunidade, realizariam outras atividades no período em que normalmente estão diante da televisão, como por exemplo, visitar um amigo, fato comum no ambiente urbano. A TV é percebida e usada pelo adolescente como um eletrodoméstico e, como tal, é dominado e não dominador.

Os adolescentes, de ambos os universos, têm comportamento semelhante no que se refere aos horários em que assistem à novela e a mesma opinião sobre a novela preferida. Ambos os grupos concentram a audiência no horário sugerido por este trabalho, ou seja, 19 horas. No universo rural, dos $84 \%$ que afirmam assistir à telenovela, $54 \%$ assistem a elas às 19 horas; $24 \%$ às 18 horas e $21 \%$ às $20 \mathrm{~h} 30 \mathrm{~min}$. Destes, $78 \%$ afirmam que a melhor novela atual é A viagem, veiculada às 19 horas. Do universo urbano, do total de $57 \%$ que afirmam assistir à novela, $50 \%$ dizem assistir às 19 horas, $33 \%$ às 18 horas e $17 \%$ às $20 \mathrm{~h} 30 \mathrm{~min}$. $A$ viagem também é a preferida deste grupo com $43 \%$ das opções.

Quanto à frequiência com que assistem a esta programação, os dois grupos se assemelham nas respostas: $53 \%$ do urbano e $58 \%$ do rural afirmam assistir "quando dá 
certo"; $42 \%$ do rural e $21 \%$ do urbano afirmam que "assistem todos os dias"; apenas no grupo urbano apareceu a alternativa "nunca", com $26 \%$.

Estas respostas refletem uma atitude descompromissada dos adolescentes com relação à telenovela. Mesmo os rurais, que têm essa programação como única atividade de lazer disponível, e mesmo afirmando que gostam desta programação, apresentam uma predisposição para outras atividades, basta que elas apareçam.

Quanto ao posicionamento crítico diante da programação, os dois universos voltam a se distanciar. O rural tem dificuldades em apontar os motivos porque gosta desse tipo de programação, o que esse gênero tem de bom e de ruim. Eles têm apenas duas posições bem claras: a primeira, quando dizem que assistir à novela faz parte da rotina diária e representa descanso e única opção de lazer. A segunda, quando dizem que "novela é novela" (Walmir, 16 anos, rural), tentando demonstrar a separação entre o universo da fantasia e o real, sinalizando também, que a telenovela está bem distante da realidade vivida por eles, demonstrando que esta consciência existe. Um exemplo claro está representado na fala de uma das adolescentes do grupo:

"A gente não pode se comportar igual às mocinhas de novela, porque ficamos mal faladas" (Fernanda, 14 anos, rural), ou ainda, na fala de um garoto: "na vida as coisas não se resolvem tão fácil como na novela" (Cléber, 15 anos, rural). Fica claro na colocação desses dois adolescentes a noção de filtro cultural, através do qual o telespectador seleciona apenas aquilo que passa pela sua vivência pessoal e concorda com seus princípios éticos e morais.
Merece destaque, que, já na adolescência, existe uma leitura crítica em relação à programação televisiva. A forma que esta crítica se constrói depende das possibilidades socioculturais que cada ambiente apresenta. Assim, quando há outros elementos socializadores, sejam eles quais forem, torna-se possível estabelecer os limites entre o mundo real vivido e o mundo ficcional apresentado na televisão, assim, "a generalização que todos se moldam à TV não vale" .

No grupo urbano, o posicionamento diante do gênero é mais claro tanto para os que o defendem quanto para os que o criticam. Um exemplo claro diz respeito à novela preferida, $A$ viagem. Alguns criticavam a representação dos espíritos em forma humana e se valiam de informações baseadas em leituras sobre a doutrina espírita. Mais uma vez, pode-se notar a influência da formação individual no entendimento dessa programação. Ficou claro, neste debate, a influência da formação religiosa de alguns destes adolescentes. Outra adolescente urbana, 16 anos, contra-argumentou em defesa do gênero: "Acho que é preciso considerar duas coisas: a primeira, é que a televisão é um meio visual, e a representação dos espíritos em forma de gente é uma solução necessária para diferenciar os personagens e suas características; a segunda, é que se a solução fosse do tipo fumacinha ou sombras teriam o grande problema com a maioria do público, pois nem todos teriam um poder de abstração suficiente para acompanhar uma novela onde grande parte dos personagens não têm forma, não têm uma cara" (Jovem de 16 anos, urbano). 
Nota-se que o posicionamento dos adolescentes urbanos é bem mais fundamentado e seu poder de argumentação é mais desenvolvido. A garota que fez a observação acima está ligada ao mundo da interpretação, pois faz parte de um grupo de teatro, e também mostrou ter um certo conhecimento sobre a linguagem do vídeo, que the tornou possível a compreensão da forma como a novela $A$ viagem apresentava os personagens do plano espiritual. A clareza com que a garota interpretou os fatos, somada ao seu histórico pessoal confirma: "a hipótese de que o senso crítico em relação à TV é incentivado quando fontes de informação, que não a própria TV, entram em ação junto ao telespectador para apresentarlhe uma interpretação diferente dos assuntos apresentados na tela" 8 .

Com os posicionamentos bem diferentes em relação à telenovela, estes adolescentes urbanos pesquisados mostraram que essa programação é vista e entendida segundo suas vivências pessoais, permeadas pela família, pela escola, pelo contexto histórico, social e político de sua região. Quanto à identificação com a realidade, a posição é semelhante ao grupo rural: a programação é vista como ficção, surgindo observações tais como: "A novela apresenta situações que acontecem na vida real; a diferença está na forma como elas são resolvidas" (André, 14 anos, grupo urbano).

Pode-se perceber que este grupo também guarda a devida distância entre a ficção e a realidade.

Adolescentes urbanos e rurais afirmam que não são influenciados pelas telenovelas ou por outro tipo de programação televisiva. Contudo, no decorrer das discus- sões, admitiram que, muitas vezes, cortam os cabelos iguais aos dos personagens, copiam modelos de roupas ou se vestem dentro do estilo lançado pela novela e também admitem usar bordões. Mesmo assim, dizem que isso não muda a personalidade de ninguém: "Se resolvo copiar uma roupa é porque gostei, acho que combina comigo, e isso é uma expressão da minha personalidade" (Vivian, 15 anos, urbano).

Percebe-se, então, que o nível de influência dessa programação está se posicionando no campo estético, no que diz respeito a modelos de beleza e ações de consumo.

A pergunta agora seria: esta imposição de estereótipos e ações consumistas não é uma forma de invadir e alterar o comportamento do público? A resposta é não. Qualquer ação neste sentido que tenha sido motivada pela programação televisiva é, na verdade, a exteriorização de uma vontade preexistente. "A força de atração do consumo em larga escala está baseada na imposição de falsas necessidades, mas na falsificação e exploração de necessidades absolutamente reais e legítimas"9.

A revista Veja ${ }^{10}$ apresentou uma reportagem com várias adolescentes que assumiram o estilo Babalu, personagem da novela das 19 horas, Quatro por quatro. A revista levantava a bandeira da influência da TV sobre as massas. Às perguntas: como o autor Carlos Lombardi criou essa personagem? Será que moças rebolantes, com microssaias e unhas vermelhas são fruto de sua brilhante imaginação? Ou são apenas a caracterização de tipos que podem ser encontra- 
dos pelas ruas da cidade?, pode-se passar às formulações: a vida está influenciando as novelas sem o menor pudor, invadindo as tramas e o trabalho de criação dos autores, impondo-lhes um comportamento extremamente cotidiano e identificável. Assim, a nossa realidade está simplesmente acabando com a arte, com o poder de abstração e criação de nossos artistas e escritores.

As afirmações acima parecem absurdas, e o são na mesma proporção do seu inverso, "os meios eletrônicos não devem seu irresistível poder a nenhum artifício ardiloso, mas à força elementar de profundas necessidades sociais, que se manifestam mesmo na atual forma depravada de tais meios"'I. Pode-se classificar as atitudes de consumo e a adoção de padrões de beleza como um tipo de influência superficial ou um tipo de botão detonador que faz exteriorizar um comportamento ou um estilo já contido. Ceder a este estímulo não forma ou deforma o caráter, o perfil ético, moral e emocional de um indivíduo. Uma novela não permanece no ar mais do que seis meses; depois mudam-se o tema, os personagens, os cenários, os atores, dirigese o foco das atenções para outras problemáticas. Assim, esse intervalo de tempo é suficiente apenas para mudar o visual e não a personalidade ou o comportamento. É suficiente para agir como um potencializador de caráter e não como formador ou deformador dele. Nem os adolescentes são tão mutáveis a ponto de se transformarem de seis em seis meses.

\section{CONCLUSÃO}

Este trabalho propôs mostrar as formas de relacionamentos entre telenovela $\mathrm{e}$ adolescentes rurais e urbanos, demonstrando a importância do meio sociocultural como fator determinante nessas relações. Acreditar cegamente que a fiç̧ão televisiva tenha o poder de moldar indivíduos, neste caso os adolescentes, é o mesmo que afirmar que a infância é inócua, e que o indivíduo chega à adolescência como uma tábula rasa, sem história, sem atividades sociais, sem vivências pessoais.

A convivência com outras instituições como família, escola, religião e amigos, entre outras, é fundamental na forma como os adolescentes se envolvem e se posicionam diante desta programação. Isto ficou claro quando foram mostradas as diferentes formas que os jovens, dos dois grupos, têm de criticar. $O$ grupo rural simplesmente gosta ou não mas, mesmo dentro de condições mais limitadas, consegue distinguir e ter uma postura crítica, separando realidade e ficção, selecionando comportamento que convém ou não ao seu meio.

Já o urbano consegue discorrer sobre o seu gostar e ver os diversos ângulos do problema, mostrando aqui a importância da formação educacional e a importância das inúmeras opções que o universo oferece aos jovens. Na leitura dessa programação, foram percebidos, também, os valores familiares e sociais, quando os adolescentes colocaram a impossibilidade de agir como personagens de novelas, sob pena de ficarem mal vistos pela sociedade. A religiosidade também esteve presente, quando se discutiram as formas de representação espiritual.

Conclui-se, então, que o adolescente relaciona-se de forma ponderada com esta programação. Tanto o urbano quanto o rural 
fazem uso de suas experiências pessoais, têm sua relação com a novela mediada pela formação sociocultural. Pode-se notar que os moldes ditados pela TV, muitas vezes confluem com as experiências pessoais ou de grupo, e possivelmente das massas, reforçando assim um valor preexistente, fato perfeitamente compreensível, já que "as premissas apresentadas pelos meios de comunicação (....) respondem às aspirações das massas" 12 .

Foi possível observar que esta programação está mais presente na vida dos adolescentes rurais, mesmo que o tempo dedicado à TV e à telenovela se assemelhem. A forma linear e contínua que o rural assiste à TV torna essa relação mais efetiva. O motivo está diretamente relacionado às características deste universo, que apresenta um leque de opções bastante limitado; apresenta o problema de distância, agravado pela difícil locomoção, impossibilitando a realização de outras atividades.

Conclui-se, também, que ambos os grupos observam a distância entre a realidade e a ficção, e que a única influência que pode ser detectada por esta pesquisa diz respeito às questões estéticas como, por exemplo, à maneira de se vestir e compor o visual. Não foi detectada nenhuma influência no que diz respeito aos valores pessoais destes adolescentes, que venham única e exclusivamente da novela.

Fica claro que o comportamento dos dois grupos não é completamente antagônico. Algumas vezes se assemelha, como por exemplo na escolha da novela preferida; outras vezes se distancia, como por exemplo na forma como usam seu tempo diante da televisão. Como já foi dito, os adolescentes urbanos assistem à programação de TV de forma fragmentada, entrecortada por outras atividades, e os adolescentes rurais assistem a ela de forma contínua.

No grupo urbano foi possível perceber que 0 adolescente até os 13 anos está mais envolvido com o gênero telenovela, comportamento que se altera a partir de $14 \mathrm{ou}$ 15 anos, devido às mudanças que a própria estrutura cotidiana destes indivíduos sofre, permanecendo mais tempo longe de casa e da televisão. Já no universo rural, essa subdivisão da adolescência não foi percebida, mantendo-se uma linearidade no comportamento do adolescente deste universo $\mathrm{em}$ relação à telenovela.

Há inúmeros trabalhos sobre recepção que demonstraram a importância das diversas instâncias de socialização do homem, como família, trabalho, escola, para a formação da postura crítica em relação à programação televisiva, porém estes trabalhos têm como objeto o adulto. Esta pesquisa mostra que já na fase da adolescência o indivíduo apresenta um grau de elaboração da realidade suficientemente crítico. Então, no que diz respeito à leitura da ficção televisiva, o adolescente apresenta um comportamento bastante próximo do comportamento adulto.

Quanto à impossibilidade de o adolescente ou de qualquer indivíduo sofrer transformações profundas no curto espaço de tempo em que determinados estereótipos permanecem no ar, fica colocada a questão do tempo nas relações indivíduo/programação televisiva.

Este trabalho caminhou no sentido de mostrar que, num curto intervalo de tempo como é o caso da telenovela brasileira -, as ações e tipos colocados para o público agem apenas como otimizadores de um comportamento já existente. 
Surgem agora outras questões: e se o telespectador fosse exposto, por um longo período, a uma mensagem, a um tipo de comportamento que fugisse de seus padrões éticos e morais, um comportamento destoante da realidade social deste indivíduo? Esta situação poderia alterar profundamente seu caráter? Quanto tempo seria necessário? Seria pertinente dizer aqui o que Enzensberger disse na década de 70 ?

"Até o momento, não existe nenhum exemplo histórico do processo de aprendizagem auto-regulador e em massa possibilitado pelos meios eletrônicos"13.

Neste caso, exposição por um longo período de tempo a uma mensagem ou tipo de comportamento destoante seria suficiente, se os outros agentes socializadores não agissem no mesmo sentido?

Estas são questões que não podem ser resolvidas neste trabalho. Para tal seria preciso uma pesquisa por um longo período envolvendo pesquisadores de diversas áreas das Ciências Humanas.

Resumo: Este estudo busca entender qual é a participação da telenovela no mundo dos adolescentes. Objetiva mostrar a importância de outras instituiçōes socializadoras, como familia, sociedade, escola e amigos, entre outras, nas formas de ver e decodificar esta programação. Os adolescentes foram pesquisados tanto no meio urbano quanto no rural, tendo em vista esclarecer como o adolescente, dentro de contextos sociais diferenciados, posiciona-se diante da temática apresentada pela telenovela brasileira.

Palavras-chave: adolescentes, telenovelas, recepção de telenovelas, recepção urbana e rural, ficção televisiva
Enquanto pesquisas assim não acontecem, muitas dúvidas com relação ao poder da televisão sobre o homem continuarão existindo. Evidentemente, este trabalho não pretende esgotar o assunto, e não diz respeito a todos os adolescentes do Brasil. Estas conclusões tratam de um grupo de adolescentes que vivem o cotidiano de uma cidade do Interior do estado de São Paulo, com suas características e peculiaridades.

Este trabalho é apenas mais um passo no sentido de desmistificar as relações entre o homem e os veículos de comunicação, diante do universo que a tecnologia vem nos impondo. Numa velocidade estonteante, assistimos à globalização, fato que não tornam inválidos os esforços de pesquisa isolados, porque só a partir da inter-relação das pequenas partes poderemos buscar o entendimento do todo (se é que isso um dia será possível) para, quem sabe, enfrentarmos de forma mais tranqüila a inevitável relação do homem com os meios de comunicação.

Abstract: This study aims at understanding what the participation of the soap opera, telenovela, is in the world of the teenagers. It hopes to show the importance of other socializing institutions, such as the family, society, school and friends, among others, relative to how this programming is decoded. The teenagers were surveyed both in the urban and rural areas, aiming at clarifying how the teenager, within the differentiated social contexts, positions himself when confronted with the subject presented by the Brazilian soap opera.

Keywords: teenagers, soap operas, soap opera reception, urban and rural reception, television fiction 